Article

\title{
Injectable Chitosan Scaffolds with Calcium $\beta$-Glycerophosphate as the Only Neutralizing Agent
}

\author{
Piotr Owczarz ${ }^{1, *(\mathbb{D}}$, Anna Rył ${ }^{1}$, Marek Dziubiński ${ }^{1}$ (1) and Jan Sielski ${ }^{2}{ }^{(0)}$ \\ 1 Department of Chemical Engineering, Lodz University of Technology, 90-924 Lodz, Poland; \\ anna.ryl@edu.p.lodz.pl (A.R.); marek.dziubinski@p.lodz.pl (M.D.) \\ 2 Department of Molecular Engineering, Lodz University of Technology, 90-924 Lodz, Poland; \\ jan.sielski@p.lodz.pl \\ * Correspondence: piotr.owczarz@p.lodz.pl; Tel.: +48-42-631-37-32
}

Received: 11 March 2019; Accepted: 16 May 2019; Published: 19 May 2019

\begin{abstract}
The presented work describes the method of preparation of thermosensitive chitosan hydrogels using calcium $\beta$-glycerophosphate salt as the only $\mathrm{pH}$ neutralizing agent and supporting the crosslinking process. The presence of calcium ions instead of sodium ions is particularly important in the case of scaffolds in bone tissue engineering. Rheological and physicochemical properties of low concentrated chitosan solutions with the addition of calcium $\beta$-glycerophosphate were investigated using rotational rheometry techniques, Zeta potential (by electrophoresis), XPS, and SEM analysis together with an EDS detector. It was found to be possible to prepare colloidal solutions of chitosan containing only calcium $\beta$-glycerophosphate (without sodium ions) undergoing a sol-gel phase transition at the physiological temperature of the human body. It has also been shown that it is possible to further enrich the obtained cellular scaffolds with calcium ions. Using the addition of calcium carbonate, hydrogels with a physiological ratio of calcium to phosphorus (1.6-1.8):1 were obtained.
\end{abstract}

Keywords: sol-gel phase transitions; injectable scaffolds; chitosan; calcium $\beta$-glycerophosphate; rheology; bone tissue engineering

\section{Introduction}

The development of tissue engineering is associated with the search for new therapies for both chronic and urgent diseases. The possibility of supporting pharmacological treatment or reconstruction of damaged tissues can be facilitated by highly porous, three-dimensional structures called scaffolds [1]. Materials used for the production of scaffolds are mostly natural or synthetic polysaccharides, bioceramics and their composites [2]. Among natural polysaccharides, chitosan is still growing in popularity. It is not without reason that it is called the 21st century polymer for biomedical applications [3-6]. Its widely known antibacterial, antifungal and antiviral properties make it a very good biomaterial for medical purposes [7-10]. In addition, this polysaccharide is characterized by bioadhesiveness, bioactivity, non-toxicity, biodegradability, cytocompatibility, and is well absorbed by living organisms $[3,11,12]$. Chitosan also has anti-inflammatory, anti-cancer, and hypolipemic and antioxidant properties [13-17]. This biopolymer, similar in terms of its chemical structure to hyaluronic acid (often used in engineering of cellular scaffolds), is much cheaper.

Thermosensitive hydrogel undergoing a sol-gel phase transition, is one of the materials used for the preparation of polymer scaffolds applied in tissue engineering [2]. The local formation of chitosan hydrogel can be induced by temperature [18-22], $\mathrm{pH}[23,24]$, or ultraviolet radiation [25]. Thermosensitive hydrogels are characterized by relatively low viscosity and predominance of viscous properties in the sol phase as well as much higher viscosity and predominance of elastic properties in the gel phase. The main difference between the two phases is the observed flow phenomenon 
characteristic of viscous fluid and the lack of flow for the viscoelastic fluid [26]. Due to their smaller invasiveness as compared to implant scaffolds, in recent years they have been the object of research by many authors [27,28]. The use of injection scaffolds makes it also possible to better fill the existing tissue defects [28]. Their additional advantage is the ability to control important properties of the scaffolds such as porosity, size, geometry, and the degree of pore in order to the mimic the topological and microstructural characteristics of the extracellular matrix (ECM) [2]. The interest in hydrogels in bone tissue engineering (BTE) is also due to their similarity to cartilage tissue which is highly hydrated and composed of chondrocytes located in type II collagen and glycosaminoglycans (GAG) [29].

Chitosan is a cationic polysaccharide that is hydrophobic at neutral $\mathrm{pH}$ of the medium, it dissolves only in an acidic environment. Chitosan hydrogel qualify as a physical gel [30] obtained by diffusion limited aggregation (DLA) [31,32]. In this case, the non-covalent interactions (van der Waals and hydrogen bonds) between the polymer chains as a result of the conversion of the polymer from hydrophilic to hydrophobic form, associated with a change in the degree of dissociation of the amino groups, are decisive. The formation of the gel network is associated with a change in the degree of dissociation (pKa) of the amino groups. Lack of positive charge causes a change (decrease) in the thickness of the solvation shell around this group and enables the aggregation of chains. The disappearance of the polyion charge leads to a change in the nature of the chain from hydrophilic to hydrophobic, and consequently, the precipitation of the chitosan from the solution and the aggregation of the polymer particles. The phase transition point of such systems is at a temperature above $50{ }^{\circ} \mathrm{C}$. Thus, it prevents their use as injection scaffolds formed in vivo. The addition of disodium glycerophosphate $\left(\mathrm{Na}_{2} \mathrm{GP}\right)$ to the chitosan solution in acid results in the formation of an unstable colloidal system (low value of Zeta potential) and a reduction in the temperature of the sol-gel phase transition point [19,32-34]. The chitosan colloidal solutions obtained by dissolving the polymer in hydrochloric acid are commonly described in the literature, however, the role of glycerophosphate is discussed $[19-22,33,35]$. The process of chitosan aggregation from solutions with glycerophosphate occurs at much lower temperatures and its kinetics depend on the current state of protonation of amino groups - the reaction-limited aggregation (RLA) [20,31,32,35]. Based on the solution of the Poisson-Boltzmann equation for chitosan (polyion) solutions containing disodium glycerophosphate (counterion), Filion and Lavertu $[20,35]$ showed that a sufficient condition for the thermal neutralization of polyion is that $\mathrm{dpK}_{0} / \mathrm{dT}<\mathrm{dpK}_{\mathrm{a}} / \mathrm{dT}$, where $\mathrm{pK}_{0}$ is the intrinsic dissociation constant of chitosan and $\mathrm{pK}_{\mathrm{a}}$ is the dissociation constant of the buffer coupled to chitosan, i.e., counterion. Furthermore, the authors stated that it is possible to use alternative compounds for glycerophosphate, which can cause thermal phase transition of chitosan systems. According to Filion and Lavertu, the key role of the buffer added to chitosan is its ability for heat-stimulated absorption of protons released from chitosan. On the other hand, Eeckman et al. [36] found that the phosphate salts containing bivalent and trivalent metal ions exert a greater influence on the lowering of the critical temperature (LCST) compared to monovalent metal salts. Also, the addition of small quantities of inert salts reduces the LCST. In this case, in addition to the concentration, the type of salt added and the valence of the anion are also important. The addition of an electrolyte can disrupt the highly ordered structure of water molecules surrounding the polyion, causing an increase in its hydrophobicity and, as a result, lowering LCST and faster precipitation of molecules from the solution, resulting in their agglomeration-forming the gel structure [36,37].

The methods for preparation of chitosan hydrogels described so far in the literature have been based on the use of disodium $\beta$-glycerophosphate [18-21]. The addition of this salt into the acidic chitosan solution causes an increase of $\mathrm{pH}$ to the physiological value (about 7 ) and a simultaneous shift of the sol-gel phase transition temperature to approximately $37^{\circ} \mathrm{C}$. The literature presents few studies on the use of glycerophosphate salts other than sodium salts, e.g., calcium $[38,39]$ and magnesium [40]. However, in all published studies, these salts have always been an addition to the commonly prepared chitosan scaffolds with disodium $\beta$-glycerophosphate never being the sole source of glycerophosphate. Moreover, the effect of calcium or magnesium ions is unclear, especially on 
rheological properties, because the introduction of both salts also causes a change (increase) in the concentration of glycerophosphate.

The use of only calcium $\beta$-glycerophosphate for the preparation of chitosan hydrogels follows from the fact that this compound potentially combines the benefits of the buffering properties of glycerophosphate as well as the replacement of sodium ions unfavorable to organisms, in particular for bone tissues, with calcium ions. The addition of glycerophosphate salt (change in $\mathrm{pH}$ of the solution) allows to reduce the sol-gel phase transition temperature [30,34,35], which is extremely important when designing scaffolds formed in vivo.

Based on researches conducted with the use of disodium glycerophosphate, it was found that the glycerophosphate residue is an osteogenic compound [41]. On the other hand, the presence of calcium ions is particularly important when thermosensitive hydrogels are used in bone tissue engineering. It results from the fact that calcium and phosphate ions are necessary to form ceramics whose structure is similar to hydroxyapatite-a mineral which together with collagen builds a scaffold responsible for mechanical properties of bone tissue [42]. Studies available in the literature $[38,39]$ discussing osteoblast cultures in chitosan hydrogels indicate that the addition of calcium $\beta$-glycerophosphate salts into commonly prepared chitosan hydrogels improves cell proliferation and viability. The quoted study also points to the non-monotonic dependence of the proliferation of osteoblast cells and their viability versus the $\beta$-glycerophosphate salt content. In studies using only calcium-phosphate bioceramics, it was found that the best conditions for the viability of osteoblasts are ensured when the calcium to phosphorus ratio was 1.6:1.0 [43]. Due to the mineral composition of bones, in the case of engineering of these tissues, there is a need to ensure an adequate ratio of calcium to phosphorus in the prepared scaffold. For this purpose, admixtures of ceramic materials are used in many scaffolds in BTE. Among the many chitosan-ceramic composites, chitosan-calcium phosphate systems are particularly popular. This is due to the similarity of their chemical composition to inorganic bone components [44]. The need to add bioceramics into the chitosan scaffolds results from their inadequate mechanical properties [45,46] and insignificant osteoconductivity of chitosan [47]. The most commonly used ceramic materials are calcium phosphate [43], $\beta$-tricalcium phosphate [48-50] and hydroxyapatite $[47,49,51-53]$. Among the compounds that can also be used to improve mechanical properties and osteoconductivity is, for example, calcium carbonate [54] which in an acidic environment dissociates to calcium ions, carbon dioxide and water.

The aim of the work was to propose a method for the preparation of chitosan scaffolds containing the addition of calcium $\beta$-glycerophosphate as the only substance neutralizing $\mathrm{pH}$ and causing a temperature decrease in the sol-gel phase transition.

\section{Materials and Methods}

Thermosensitive colloidal chitosan solutions were prepared by dissolving $400 \mathrm{mg}$ of crab-derived chitosan (Sigma-Aldrich, Poznan, Poland, product number: 50494) in $20 \mathrm{~mL}$ of $0.1 \mathrm{M}$ acetic acid (Sigma-Aldrich, Poznan, Poland, product number: 695092). The thoroughly mixed solution was left for $24 \mathrm{~h}$ to allow the polysaccharide to completely dissolve. Next, a suspension of calcium $\beta$-glycerophosphate cooled for $2 \mathrm{~h}$ was added dropwise to the chitosan acetate solution. The suspension was obtained by mixing from $0.2 \mathrm{~g}$ to $2.0 \mathrm{~g}$ of salt in such an amount of distilled water (from $1 \mathrm{~mL}$ to $5 \mathrm{~mL}$ ) as to obtain the appropriate molar concentrations of calcium- $\beta$-glycerophosphate salt, as shown in Table 1.

The basic physicochemical parameters of chitosan such as the degree of deacetylation and molecular weight were determined using the titration method and gel permeation chromatography. The degree of deacetylation was determined as a difference $\mathrm{DD}=1$-DA. The degree of acetylation (DA) was determined by titrimetric method. The molecular weight $(\mathrm{Mw})$ of the tested samples was determined by gel permeation chromatography (GPC/SEC) with the use of high-performance liquid chromatography (HPLC) on a Knauer Smartline company apparatus, equipped with an analytical isocratic Pump1000 and DRI detector (S-2300/2400, Knauer, Berlin, Germany). The studies carried out 
indicated that the degree of deacetylation of chitosan was $\mathrm{DD}=81.8 \%$, and the average molecular weight was $\mathrm{Mw}=680 \mathrm{kDa}$.

Table 1. The composition of the solutions used in the studies with their designations.

\begin{tabular}{ccc}
\hline \multirow{2}{*}{$\begin{array}{c}\text { The Molar Concentration of } \\
\beta-C a G P\end{array} \mathbf{m o l}^{\left.\mathbf{2} \mathbf{d m}^{3}\right]}$} & \multicolumn{2}{c}{ Sample Number } \\
\cline { 2 - 3 } & Without $\mathrm{CaCO}_{3}$ & With $\mathrm{CaCO}_{3}$ \\
\hline 0.00 & 1 & $1 \mathrm{CC}$ \\
0.05 & 2 & $2 \mathrm{CC}$ \\
0.10 & 3 & $3 \mathrm{CC}$ \\
0.19 & 4 & $4 \mathrm{CC}$ \\
0.38 & 5 & $5 \mathrm{CC}$ \\
\hline
\end{tabular}

In order to increase the ratio of calcium ions to phosphorus ions in the solution, calcium carbonate was added before introducing calcium $\beta$-glycerophosphate into the colloidal solution (Ubichem, Redditch, UK, product number: $\mathrm{C} 044 \mathrm{H})$. The use of an appropriate amount of salt was to ensure the assumed molar ratio of calcium to phosphorus ions is equal to 1.6:1.

\subsection{Characteristics of the Mechanical Properties of Thermosensitive Hydrogels}

Rheological measurements of the obtained solutions were carried out using the Anton Paar Physica series MCR301 (Anton Paar, Warszawa, Poland) rotational rheometer with a cone-plate measuring system (50 mm cone diameter, $1^{\circ}$ cone angle and $48 \mu \mathrm{m}$ cone truncation). In order to determine viscoelastic properties, measurements were carried out under isothermal conditions in a wide range of angular frequencies $\left(\omega=0.005 \mathrm{~s}^{-1}-500 \mathrm{~s}^{-1}\right)$ at temperatures of $5{ }^{\circ} \mathrm{C}, 25^{\circ} \mathrm{C}, 30^{\circ} \mathrm{C}, 35^{\circ} \mathrm{C}$, and $40{ }^{\circ} \mathrm{C}$. The conditions of the sol-gel phase transition were also determined by performing non-isothermal oscillatory measurements at a constant heating rate $(1 \mathrm{deg} / \mathrm{min})$ in the range $5{ }^{\circ} \mathrm{C}-60^{\circ} \mathrm{C}$ and isothermal measurements at $37^{\circ} \mathrm{C}$. In both cases a constant deformation value was used (angular frequency $\omega=5 \mathrm{~s}^{-1}$, strain amplitude $\gamma=1 \%$ ).

\subsection{Stability of Colloidal Solutions (Zeta Potential) and $\mathrm{pH}$ Measurements}

The Zeta potential changes, indicating the stability of the tested solutions, were determined using Malvern ZetaSizer Nano ZS (Malvern Instruments Ltd., Malvern, UK) with a folded capillary cell DTS1060 type. The measurements were carried out in non-isothermal conditions every $1 \mathrm{~K}$ in the temperature range $5-50{ }^{\circ} \mathrm{C}$ (heating rate $1 \mathrm{~K} / \mathrm{min}$ ). A series of 100 measurements were carried out for each temperature and the results were averaged.

The $\mathrm{pH}$ measurements of the sol phase were conducted at $4{ }^{\circ} \mathrm{C}$ using a pH-meter ELMETRON CP-401 (ELMETRON Sp. j., Zabrze, Poland), equipped with a dedicated electrode for viscous liquids ERH-12-6.

2.3. SEM Morphology and Analysis of the Atomic Composition of the Surface Layer with the Energy-Dispersive X-ray Spectroscopy Technique

The morphology of scaffolds was analyzed using the scanning electron microscope SEM (FEI, Quanta 200F, Hillsboro, OR, USA). With the use of an EDS detector (Oxford Instruments, X-Max, Manchester, UK), an analysis of the atomic composition of the surface layer of the scaffolds obtained was also carried out. During the tests, an energy beam of $3.5 \mathrm{eV}$ was used. The measurements were carried out under low vacuum (about $100 \mathrm{~Pa}$ ) in nitrogen atmosphere.

\subsection{Analysis of Surface Composition by the X-ray Photoelectron Spectroscopy Technique}

The atomic composition of the tested material was analyzed using the XPS AXIS Ultra spectrometer from Kratos Analytical Ltd. (Manchester, UK). For the analyzed samples, emission spectrum was made 
in the full binding energy range from 1200 to $0 \mathrm{eV}$. The measurements were carried out at an absolute pressure of $1 \times 10^{-6} \mathrm{~Pa}$.

\section{Results and Discussion}

\subsection{Calcium Glycerophosphate Versus Disodium Glycerophosphate}

Measurements determining the effect of the glycerophosphate salt cation on viscoelastic properties and the stability of colloidal systems were carried out for the same molar concentrations $\left(0.38 \mathrm{~mol} / \mathrm{dm}^{3}\right)$ and were based on the concentration of the sodium glycerophosphate salt most commonly used in the literature.

The effects of the addition of glycerophosphate salt and the type of cation contained in this salt were determined by measurement of Zeta potential. The obtained results are shown in Figure 1. The value of the electrophoretic mobility of the particles in the electric field and the value of $\zeta$-potential determined on the basis of the Henry equation can be used to compare the dispersion stability of the colloid systems studied [55]. This stability is defined as the result of the sum of attractive forces (Van der Waals, hydrogen bonds) and repulsive forces (electrostatic forces). Based on the changes in the Zeta potential obtained for the solution without glycerophosphate, in all of the tested temperatures, the particles in the suspension had a high positive potential, $40-50 \mathrm{mV}$, which indicates a system with good stability. Moreover, the Zeta potential value increases with increasing temperature. According to the interpretation adopted in the literature [55], this indicates that they do not tend to repel each other or tend to agglomerate. In the case of solutions containing the addition of glycerophosphate salt, the measured $\zeta$-potential values are much lower, $3-12.5 \mathrm{mV}$ for disodium glycerophosphate and 0-13.5 mV for calcium glycerophosphate. The low values of the Zeta potential of the molecules indicates that the solution containing them is an unstable system. The macromolecules are beginning to attract each other and aggregation occurs. The influence of the addition of glycerophosphate on the stability of chitosan (chloride) solutions was confirmed in the study by Owczarz and coworkers [32].

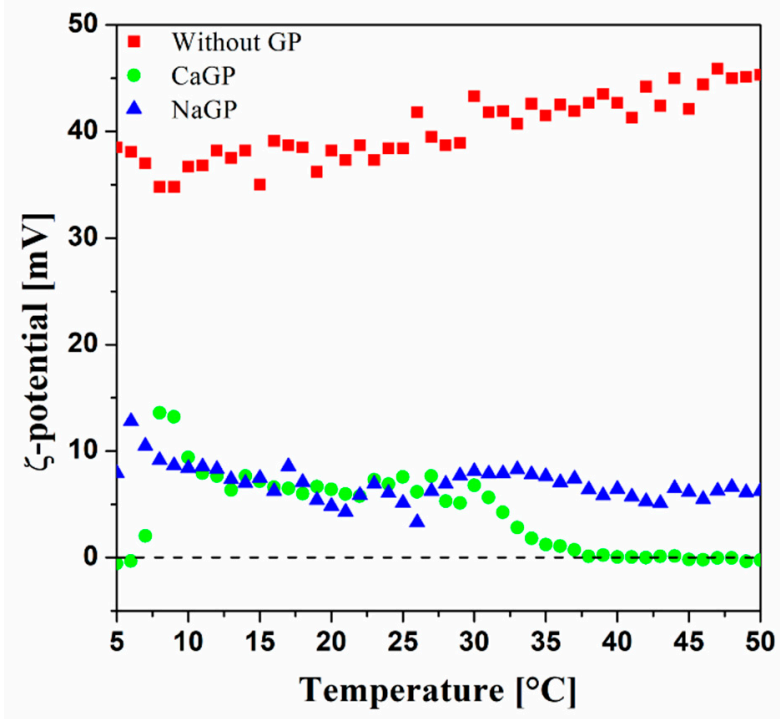

Figure 1. Experimental curves of Zeta potential for samples without glycerophosphate, with disodium glycerophosphate and calcium glycerophosphate under non-isothermal conditions.

The analysis of Zeta potential curves for samples with the addition of glycerophosphate salts shows that at temperatures below $30^{\circ} \mathrm{C}$, the value decreases with increasing temperature, from 12.8 to 6.9 and from 13.6 to $6.69 \mathrm{mV}$ for sodium and calcium glycerophosphate, respectively. Moreover, it does not depend on the type of salt used. Significant differences in the obtained Zeta potential curves are visible in the gelation region (above $30^{\circ} \mathrm{C}$ ). In the case of solutions containing the commonly used 
disodium glycerophosphate salt, further heating of the experimental medium did not change the value of the $\zeta$-potential and thus the stability of the system. According to the authors [55], such systems should be classified as highly unstable systems. In contrast, in the case of calcium glycerophosphate salts, with the temperature ranging from $30^{\circ} \mathrm{C}$ to $37^{\circ} \mathrm{C}$, a further decrease in the Zeta potential to $0 \mathrm{mV}$ was observed-the system is in the phase of coagulation of colloidal particles [55]. Thus, the conducted research allowed to clearly determine that the type of glycerophosphate salt (the valency of the cation forming it) has an important role in the stability of the colloidal system [56].

Analysis of the results of isothermal measurements made for samples 1-5 in a wide range of angular frequencies $\omega$, indicates that the use of the highest concentration of $\beta$-glycerophosphate, corresponding to the commonly used molar sodium salt concentration $[19,33]$, causes a significant change in the dominant properties of the medium—cf. Figure 2a,b. Already at $5{ }^{\circ} \mathrm{C}$, almost in the entire range of angular frequencies, the predominance of elastic properties over viscous ones is observed-the system shows properties characteristic of the gel; shown in Figure 2a.
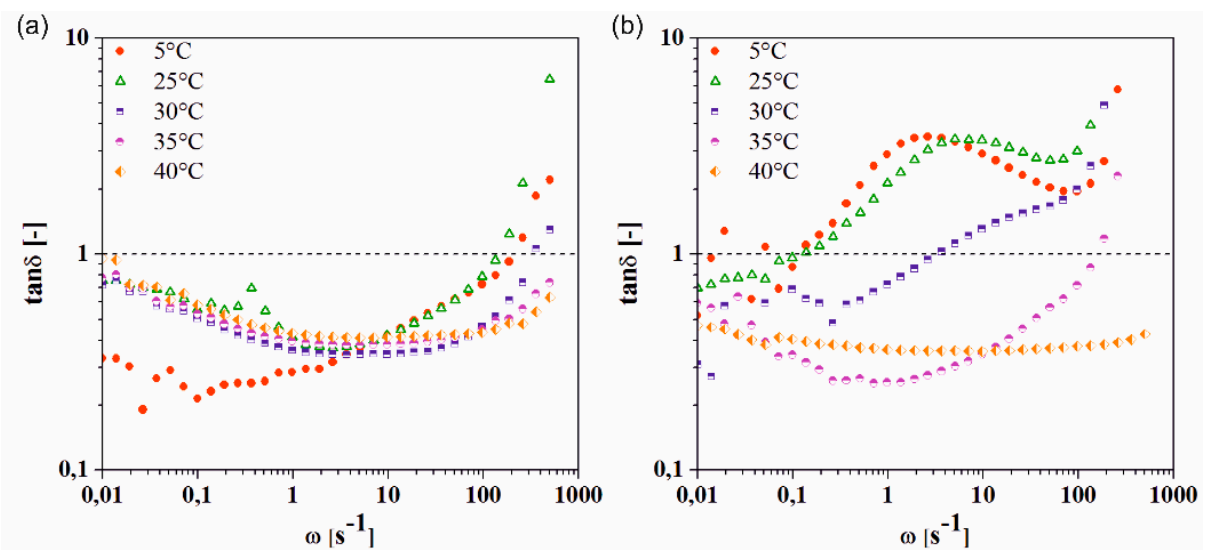

Figure 2. Comparison of mechanical spectra of colloidal chitosan solutions with calcium $\beta$-glycerophosphate (a) and sodium $\beta$-glycerophosphate (b).

Moreover, based on the non-isothermal rheological measurements, it was found that the use of calcium glycerophosphate salt concentration similar to the concentration of sodium glycerophosphate commonly used in the literature [33], caused a significant lowering of the sol-gel phase transition point. The use of the same concentration and thus an equal amount of phosphate residues derived from $\beta$-glycerophosphate decreased the temperature of the sol-gel transition point from $39^{\circ} \mathrm{C}$ to about $18{ }^{\circ} \mathrm{C}$.

\subsection{Optimal Concentration of Calcium Glycerophosphate}

Due to such a violent change in the viscoelastic properties of colloidal chitosan solutions as well as the gelation conditions, it was necessary to determine the optimal concentration of calcium glycerophosphate salt in order to ensure adequate properties for the injection application of the tested chitosan solutions $\left(G^{\prime}<G^{\prime \prime}\right)$, i.e., the predominance of viscous features at low temperatures and the expected sol-gel phase transition at about $37^{\circ} \mathrm{C}$. The results of non-isothermal measurements of rheological properties of colloidal chitosan solutions with various concentrations of calcium $\beta$-glycerophosphate are shown in Figure 3.

It was found that the dependence of calcium $\beta$-glycerophosphate salt concentration on the temperature of gelation of chitosan hydrogels, are, as to the direction, consistent with the studies on sodium $\beta$-glycerophosphate salt presented in the literature [33,57]. It means that the change in the cation in the glycerophosphate salt does not change the quality of the obtained results; clearly, the same effect of the increase in concentration on the reduction of the gelation temperature is observed. However, obtained phase transition temperatures are significantly lower than when sodium glycerophosphate salts are used. 

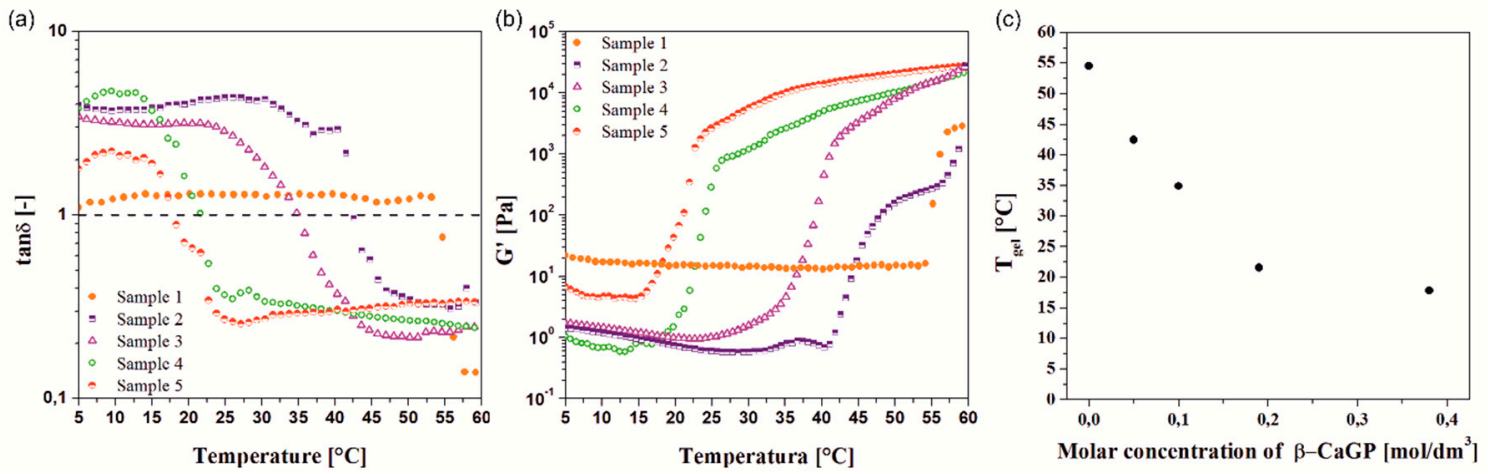

Figure 3. The effect of calcium $\beta$-glycerophosphate on (a) the curve of damping factor tan $\delta$ in non-isothermal conditions, (b) the change of storage modulus $G^{\prime}$ under non-isothermal conditions, and (c) the dependence of sol-gel phase transition temperature.

Analysis of changes in the experimental curve and the obtained values of storage modulus $\mathrm{G}^{\prime}$ as a function of temperature (Figure $3 \mathrm{~b}$ ) indicate that the addition of calcium glycerophosphate salt reduces the mechanical resistance at low temperatures, but finally leads to its increase in the gel phase.

Reduction of the content of calcium glycerophosphate salt caused a gradual change of the dominant properties of the medium to viscous ones at low temperatures and an increase of phase transition temperature. It was found that the optimal parameters had a colloidal chitosan solution containing $0.1 \mathrm{~mol} / \mathrm{dm}^{3}$ of calcium $\beta$-glycerophosphate-sample 3. This solution has thermosensitive properties, as shown in Figure 4f. It is visible that the sol phase was maintained up to a temperature of about $25^{\circ} \mathrm{C}$. Subsequent heating of the solution led to its structural change which is observed in the case of non-isothermal (Figure 3a) and isothermal experimental curves (Figure 4c-e). The determined sol-gel phase transition point as a crossover point of storage $\left(G^{\prime}\right)$ and loss $\left(G^{\prime \prime}\right)$ moduli curves occurred at $35^{\circ} \mathrm{C}$ (Figure 3a). A complete formation of the structure occurred at above $40^{\circ} \mathrm{C}$. Furthermore, it was found that with the formation of an unlimited three-dimensional structure, improvement of the mechanical properties of the obtained scaffold was visible. This is seen as a plateau in the curve of changes in the value of the storage modulus $G^{\prime}$ at angular frequency $\omega-c$ f. Figure $2 b$. This is also confirmed by the values of $G^{\prime}$ modulus which are much higher than the ones obtained in the experiments carried out at lower temperatures. The storage $\mathrm{G}^{\prime}$ and loss $\mathrm{G}^{\prime \prime}$ moduli at $5{ }^{\circ} \mathrm{C}$ are shown in Figure $4 \mathrm{a}$ and represent a highly flexible region in which a network structure is formed and a glass transition region occurs between the highly flexible and glassy state $[56,57]$. As the temperature of the measurement increases, the obtained experimental curves are shifted towards the strong dominance of the glass transition region. At $35^{\circ} \mathrm{C}$ and $40{ }^{\circ} \mathrm{C}$, experimental curves characteristic of the glassy state are observed [58].

Analysis of damping factor- $\tan \delta=\mathrm{G}^{\prime \prime} / \mathrm{G}^{\prime}$, (see Figure $4 \mathrm{f}$ ) allows us to state that for the measurements carried out at temperatures of $5{ }^{\circ} \mathrm{C}$ and $25^{\circ} \mathrm{C}$, the analyzed polysaccharide solution is characterized by high molecular weight and the presence of long side chains. The difference in the value of $\tan \delta$ is due to the decrease in mechanical resistance characterized by storage modulus $G^{\prime}$. This biopolymer occurs in both temperatures in an amorphous form. At $30^{\circ} \mathrm{C}$, the curve becomes flattened, which may indicate gradual structural changes occurring in the studied medium-the occurrence of a weakly crosslinked, amorphous biopolymer, a so-called soft rubber. At the highest temperatures of $35^{\circ} \mathrm{C}$ and $40^{\circ} \mathrm{C}$, a change in the structural form of the medium is observed. In the whole range of angular frequencies $\omega$, elastic properties predominate over viscous ones $\left(G^{\prime}>G^{\prime \prime}\right)$. For measurements carried out at $40^{\circ} \mathrm{C}$, it was found that the mean value of the tangent of loss angle $\tan \delta$ was about 0.3 . This indicates the occurrence of a polymer in a glassy form. 

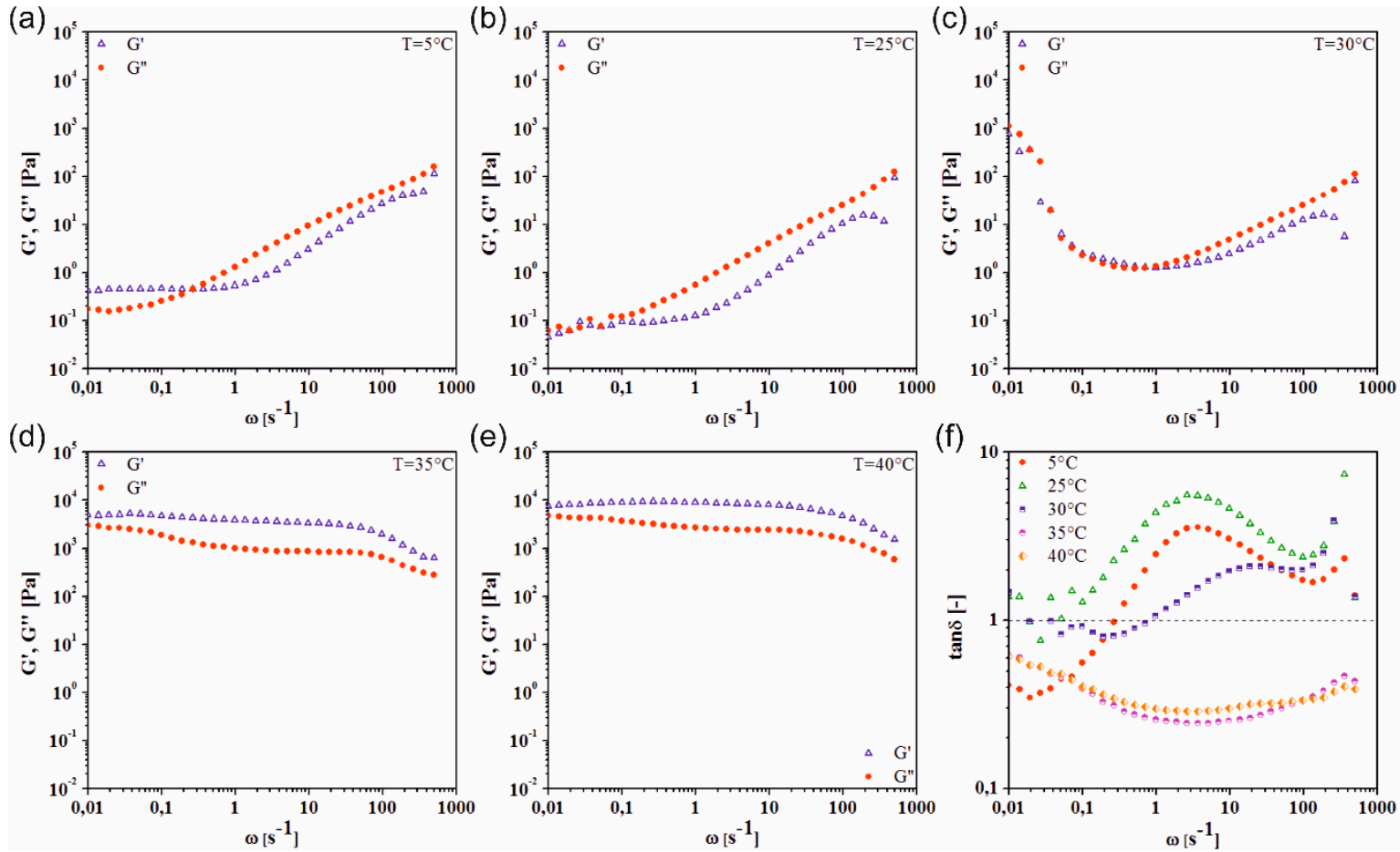

Figure 4. Relations of storage $G^{\prime}$ and loss $G^{\prime \prime}$ moduli (a-e) and damping factor $\tan \delta(\mathbf{f})$ as a function of angular frequency $\omega$ for sample 3 at different temperatures.

Table 2 presents the results of measurements of the sol-gel phase transition kinetics determined at $37^{\circ} \mathrm{C}$. It has been found that the use of a higher concentration of calcium- $\beta$-glycerophosphate leads to a shorter time needed to form the spatial structure of the polymer network. Simultaneously, it should be noted that for samples 4 and 5, although the time of scaffold formation is short, the phase transition temperature is too low. For these samples, there is a risk of starting the gelation process at room temperature. This is connected with a significant increase in the viscosity of the system, and thus difficult injection application.

Table 2. Results of non-isothermal and isothermal measurements for the tested samples and analysis of the gelation kinetics curve.

\begin{tabular}{|c|c|c|c|c|c|c|}
\hline \multirow{2}{*}{ Sample } & \multirow{2}{*}{$\mathrm{pH}$} & \multirow{2}{*}{$\begin{array}{l}\text { Non-Isothermal } \\
\text { Measurements } \\
\text { Tgel }\left[{ }^{\circ} \mathrm{C}\right] \text { Based } \\
\text { on F-L Method }\end{array}$} & \multicolumn{2}{|c|}{ Isothermal Measurements } & \multicolumn{2}{|c|}{$\begin{array}{c}\text { Analysis of the Gelation } \\
\text { Kinetics Curve }\end{array}$} \\
\hline & & & $\begin{array}{l}\text { Tgel [s] Based on } \\
\text { tan = } 1 \text { Method }\end{array}$ & $\begin{array}{c}\text { Value of } G^{\prime} \\
{[\text { Pa] for } \tan =1}\end{array}$ & $\begin{array}{l}\mathrm{G}_{\min }^{\prime}[\mathrm{Pa}] \\
\text { Value }\end{array}$ & $\begin{array}{c}\text { Reference } \\
\text { Time [s] }\end{array}$ \\
\hline 1 & 5.03 & 54.9 & & Not tested & & \\
\hline 2 & 5.88 & 43.1 & 2760 & 5.52 & 0.16 & 2681 \\
\hline 3 & 6.29 & 35.4 & 700 & 3.24 & 0.11 & 810 \\
\hline 4 & 6.58 & 22.0 & 163 & 2.18 & 0.15 & 121 \\
\hline 5 & 6.78 & 18.0 & 145 & 23.10 & 1.00 & 87 \\
\hline $1 C C$ & 6.17 & $54.0 *$ & & Not tested & & \\
\hline $2 \mathrm{CC}$ & 6.19 & 39.2 & 1873 & 7.21 & 0.79 & 1733 \\
\hline $3 C C$ & 6.21 & 29.6 & 403 & 5.96 & 0.61 & 580 \\
\hline $4 \mathrm{CC}$ & 6.48 & $17.2 *$ & $*$ & $*$ & $*$ & $*$ \\
\hline $5 C C$ & 6.73 & $13.0 *$ & * & $*$ & * & $*$ \\
\hline
\end{tabular}

Samples 1 and 1CC were not tested in isothermal measurements, due to the too long expected measurement time. * Samples which in the entire measuring range were characterized by predominance of elastic properties over viscous ones.

In order to normalize the obtained data, an analysis was performed in which the reference time of fast gelation was determined; shown in Figure 5a. This value was defined as a difference between the 
time of reaching the same value of storage modulus $G^{\prime}$ for all tested samples at the fast gelation region (determining the same state of material elasticity), and the time of reaching the minimum value of storage modulus $G^{\prime}$, which is identified with the end of the viscoelastic flow phase and the start of the fast gelation stage [19]. The set value of storage modulus $\mathrm{G}^{\prime}$ was chosen so that for all cases it was above the gelation point defined as the intersection point of the curves of $G^{\prime}$ and $G^{\prime \prime}$ moduli. In the considered cases, it was $\mathrm{G}_{\mathrm{REF}}^{\prime}=50 \mathrm{~Pa}$. The analysis shows that the reference time of fast gelation is a non-linear, decreasing function of the calcium $\beta$-glycerophosphate concentration-cf. Figure $5 \mathrm{~b}$.
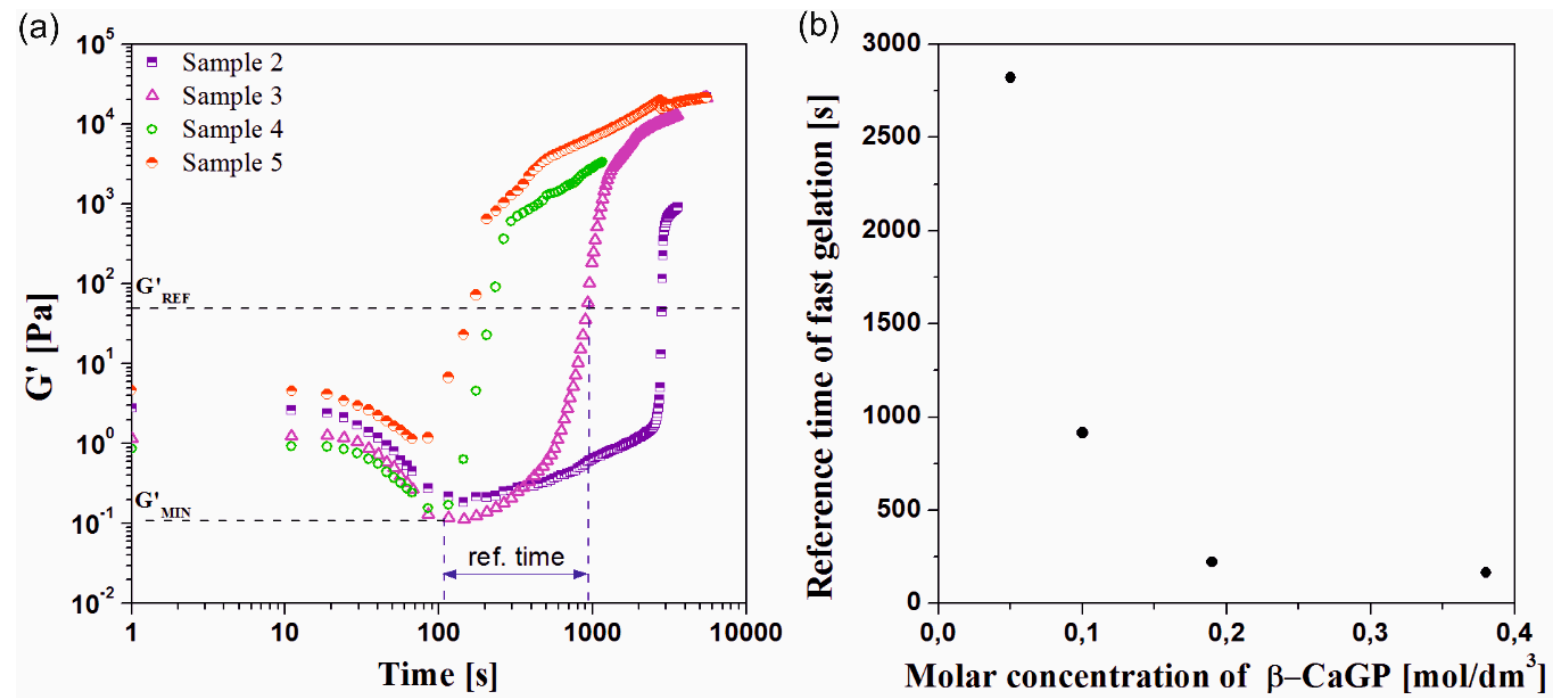

Figure 5. Kinetics of changes in the value of storage modulus $G^{\prime}$ along with the presentation of a method for determining the reference time of rapid gelation (a) and the dependence of the reference time of gelation on molar concentration of calcium- $\beta$-glycerophosphate (b).

\subsection{Enrichment with Calcium Ions}

In order to increase the proportion of calcium in relation to the content of phosphorus to a similar ratio naturally occurring in bone tissue i.e., 1.6/1, the calcium carbonate was added to the colloidal solution of chitosan. The presence of calcium carbonate in the solution was in each case associated with a change in the mechanical properties of the tested solutions; however, this effect depended on the concentration of calcium glycerophosphate salt.

The experimental curves of $G^{\prime}$ and $G$ moduli for sample 3 (Figure 6a-c), which underwent phase transition in conditions similar to the physiological temperature of the human body (cf. Figure 3a) and the corresponding sample containing calcium carbonate, sample 3CC (Figure $6 \mathrm{~d}-\mathrm{f}$ ), are shown in Figure 6. Analysis of the results of measurements of oscillating spectra obtained at temperatures up to $25{ }^{\circ} \mathrm{C}$ allowed us to state that in both solutions, samples 3 (Figure 6a) and samples 3CC (Figure 6d), the predominance of viscous features over elastic properties is visible $\left(G^{\prime}<G^{\prime \prime}\right)$. Slight changes in the experimental curves of storage $G^{\prime}$ and loss $G^{\prime \prime}$ moduli, as compared to sample 3, are observed in the range of low angular frequency $\omega$ for measurements carried out at temperatures $5^{\circ} \mathrm{C}$ and $25^{\circ} \mathrm{C}$. Further heating of samples 3 and $3 \mathrm{CC}$ to $30^{\circ} \mathrm{C}, 35^{\circ} \mathrm{C}$ and $40^{\circ} \mathrm{C}$ leads to changes in the curves of storage and loss moduli; cf. Figure 6. The addition of calcium carbonate to sample 3 (which gives the composition of sample 3CC) results in the occurrence of characteristic shapes of the curves of storage $\mathrm{G}^{\prime}$ and loss $\mathrm{G}^{\prime \prime}$ moduli, cf. Figure $6 \mathrm{~b}-\mathrm{e}$, towards a stronger domination of the glass transition and glassy state regions [58-60]. The addition of calcium carbonate results in obtaining for sample 3CC similar experimental curves for storage $G^{\prime}$ and loss $G^{\prime \prime}$ moduli that were obtained for sample 3 in the case of tests carried out at lower temperatures; cf. Figure 6. 

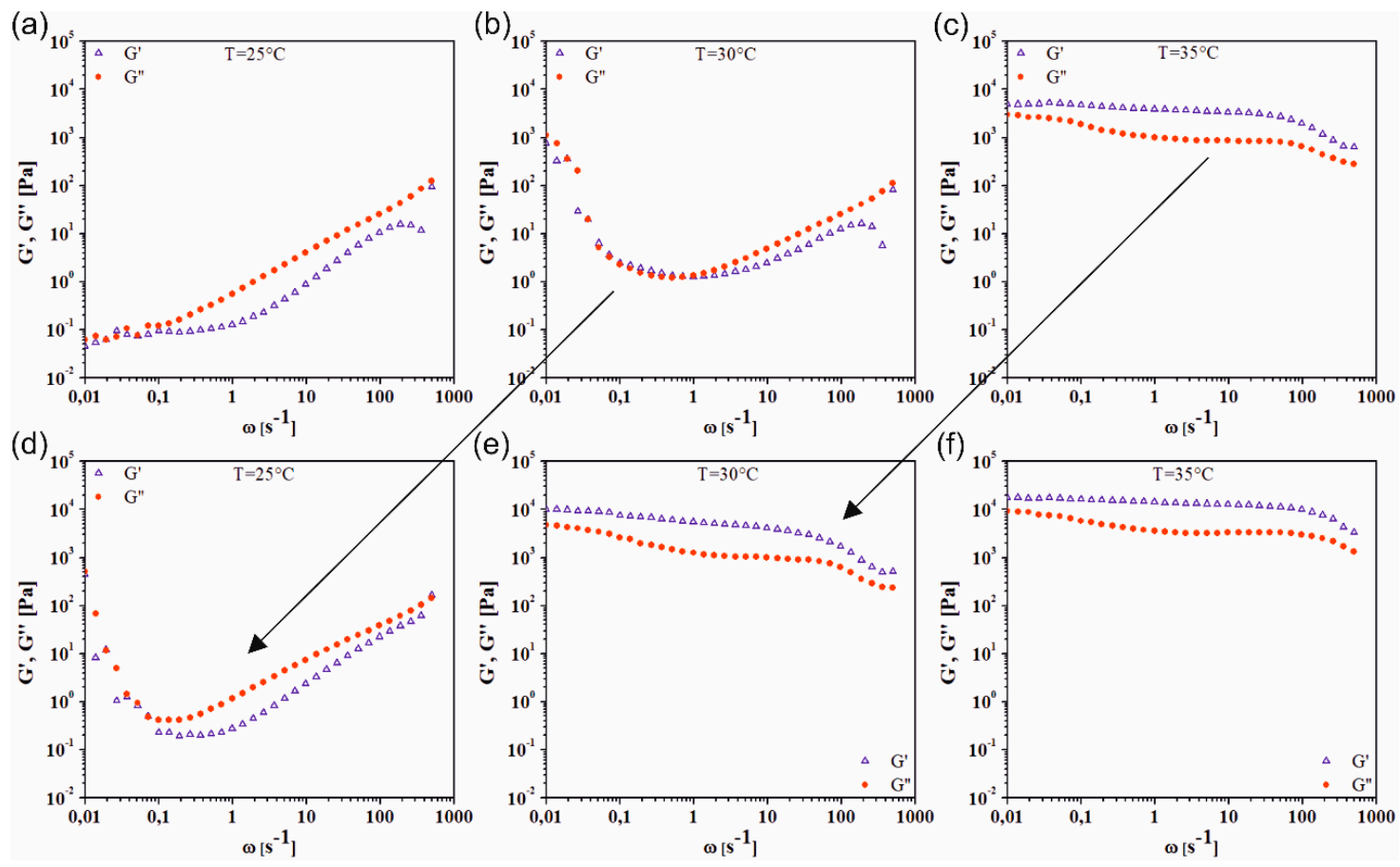

Figure 6. Comparison of experimental curves for storage $\mathrm{G}^{\prime}$ and loss $\mathrm{G}^{\prime \prime}$ moduli for sample 3 (a-c) and sample $3 \mathrm{CC}(\mathbf{d}-\mathbf{f})$ at $25^{\circ} \mathrm{C}, 30^{\circ} \mathrm{C}$ and $35^{\circ} \mathrm{C}$.

Performing analogous analyses for samples 4 and 5, it was found that in the case of sample 5, the addition of calcium carbonate (sample 5CC) increased the mechanical resistance of the obtained media at all tested temperatures. Simultaneously, there were no distinctly different experimental curves of storage modulus $G^{\prime}$ and changes in the rheological properties of the medium. Samples 5 and $5 C C$ were characterized by the predominance of elastic properties over viscous ones already at low measuring temperatures. The addition of calcium carbonate salt to sample 4 (sample 4CC) was related to a rapid change in its viscoelastic properties at low measuring temperatures. Analyzing the results of tests conducted at $5{ }^{\circ} \mathrm{C}$ for sample $4 \mathrm{CC}$, it was found that for a solution containing an additional source of calcium, the predominance of elastic properties over viscous properties was observed. At the same time, it was found that the improvement of mechanical properties of sample 4CC caused by the addition of calcium carbonate, was not as significant as in the case of sample 5CC.

The effect of the addition of calcium carbonate on the conditions of sol-gel phase transition was determined based on the analysis of the results of non-isothermal oscillatory measurements. However, only in the case of 2CC and 3CC solutions it was possible to determine the sol-gel phase transition temperature as the intersection point of the dynamic modules $(\tan \delta=1)$. The remaining solutions containing the calcium carbonate were characterized by the predominance of elastic properties over viscous ones already at low temperature, hence it was not possible to apply the above method to determine the gelation temperature. For this reason, the method proposed by Fredrickson and Larson [61] was used. This theory is based on the order-disorder of block copolymers considering the aggregation of hydrophobic acetylated blocks of chitosan chains in systems with glycerophosphate [34,62], and it can be successfully applied even in the case of systems with dominance of elastic properties over viscous ones. As a consequence, the dependence of temperature as a function of the glycerophosphate concentration with the addition of calcium carbonate was determined. It is clearly visible that in each case the addition of calcium carbonate reduces the sol-gel phase transition temperature; see Figure $7 \mathrm{~b}$.

Taking into account the application aspect, the use of solutions with a predominance of elastic properties seems to be disadvantageous because their injection can be difficult and cause discomfort to the patient. On the other hand, the 1CC sample undergoes a phase transition at too high a temperature 
which will prevent the formation of the scaffold structure in vivo. Consequently, the best solution seems to be using a 3CC sample, whose phase transition temperature is around 30C. Simultaneously, this sample undergoes a sol-gel phase transition in the typical form (from dominance of viscous properties at low temperature, to dominance of elastic properties at high temperature).
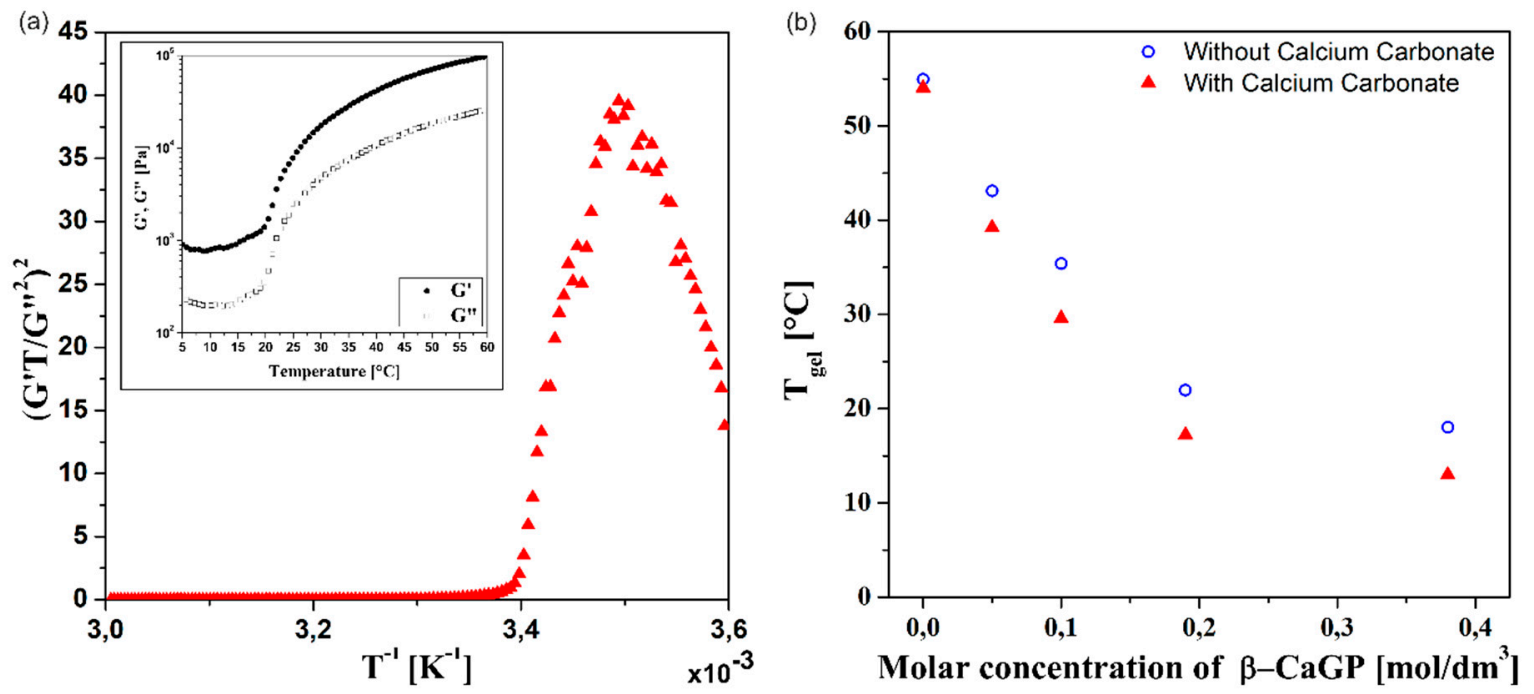

Figure 7. (a) Application of the Fredrickson-Larson method to determine the phase transition point for the medium with the predominance of elastic properties-sample 5CC. (b) Effect of the addition of calcium carbonate on the gelation temperature.

In the case of sample 3CC, the predominance of viscous properties over elastic properties is observed in measurements carried out at low temperatures. Differences in the experimental curves of mechanical spectra in the temperature range of $25^{\circ} \mathrm{C}$ to $35^{\circ} \mathrm{C}$, as shown in Figure 6, are confirmed by non-isothermal measurements of gelation point temperature, cf. Figure 8a. Equalization of the values of storage $G^{\prime}$ and loss $G^{\prime \prime}$ moduli (the gelation point of sample $3 \mathrm{CC}$ ) takes place at about $30^{\circ} \mathrm{C}$, as shown in Figure 8a. For comparison, in the case of sample 3, without the addition of calcium carbonate, the obtained sol-gel phase transition temperature is about $5^{\circ} \mathrm{C}$ higher, as shown in Figure 6 a. Differences in the sol-gel phase transition temperatures result from different viscoelastic properties of both media-cf. Figure $6 \mathrm{c}, \mathrm{e}$.

The introduction of an additional source of calcium also caused a significant increase in the mechanical resistance of the medium tested; shown in Figure $8 \mathbf{b}$ and Table 3. A particularly large difference in the values of modulus $\mathrm{G}^{\prime}$ is observed at $37^{\circ} \mathrm{C}$. This is due to the fact that at this temperature, both samples are in different phases of the gelation process. Sample 3, devoid of calcium carbonate addition, occurs in the area of fast gelation, while sample 3CC is already in the slow gelation region [57]. Comparison of results obtained for the isothermal measurements indicates that the addition of calcium carbonate (sample 3CC) shortens the time after which intersection of the curves of storage and loss moduli was observed, with a simultaneous increase in the value of storage modulus G' (Table 2). The presence of calcium carbonate also shortens the reference time of fast gelation.

The critical role of glycerophosphate ions on the formation of three-dimensional spatial structure was confirmed by rheological tests for a sample containing calcium carbonate and is devoid of calcium $\beta$-glycerophosphate-sample 1CC. Analysis of changes in the values of storage modulus $G^{\prime}$ obtained in non-isothermal measurements (Figure $8 \mathrm{~d}$ ) indicates that despite the dominance of the elastic properties of the medium at low temperatures, formation of a three-dimensional cross-linked structure is possible only at temperatures above $55{ }^{\circ} \mathrm{C}$. The determined temperature (position of the gelation point) is comparable with the phase transition temperature of the colloidal chitosan solution without the calcium $\beta$-glycerophosphate and calcium carbonate. This means that the introduction of a different type of salt 
into the solution without the addition of calcium $\beta$-glycerophosphate ( $\mathrm{pH}$ buffering) does not provide the possibility to form a three-dimensional cross-linked structure at temperatures below $40{ }^{\circ} \mathrm{C}$, and at low temperatures it causes only changes in the properties of the experimental medium from a viscous fluid to the fluid with predominant elastic properties; shown in Figure 8c.

(a)

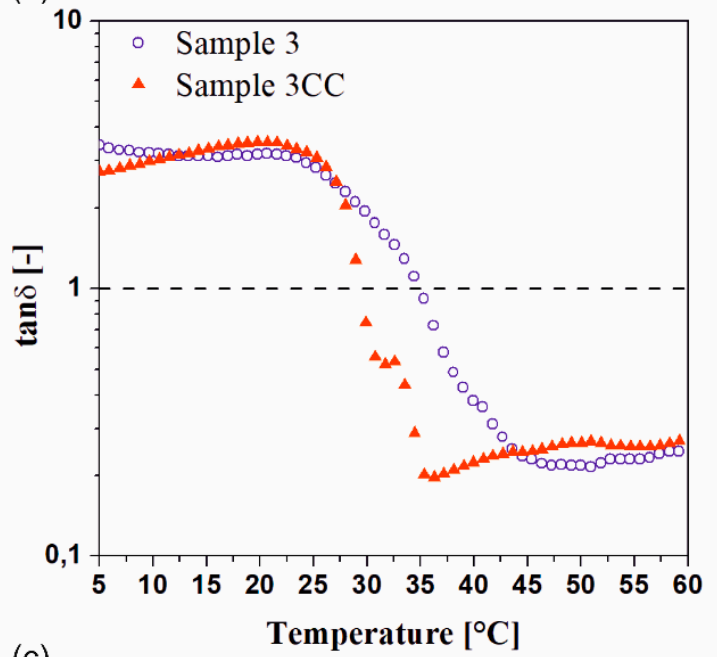

(c)

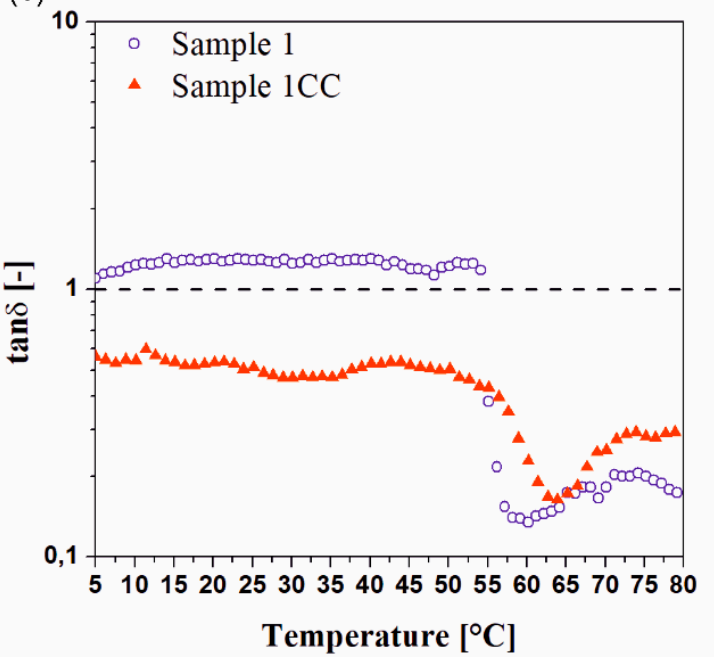

(b)

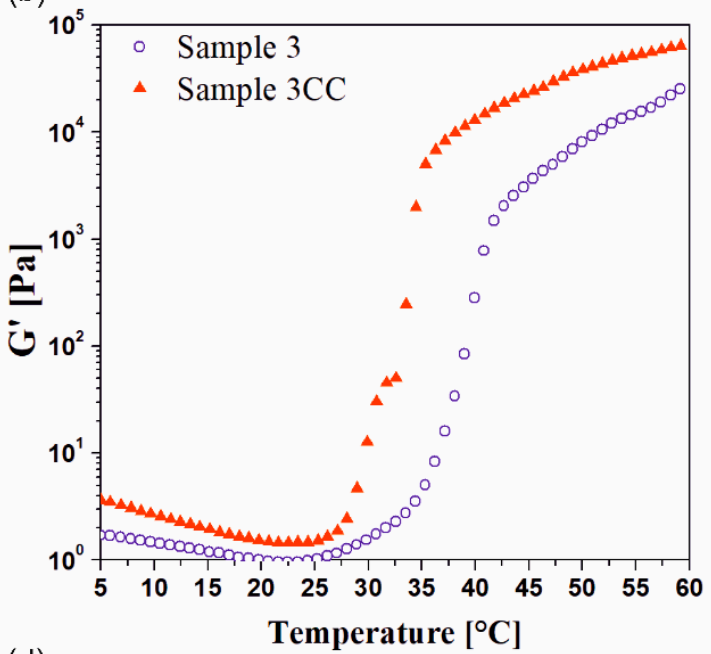

(d)

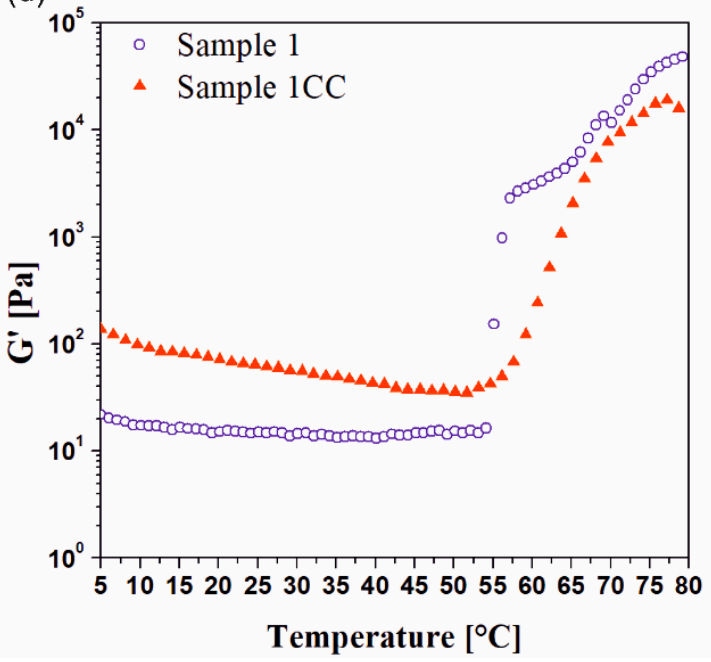

Figure 8. Experimental curves $\tan \delta$ as a function of temperature for sample 3 and $3 C C(\mathbf{a})$, and sample 1 and 1CC (c). Experimental curves of storage modulus $\mathrm{G}^{\prime}$ as a function of temperature for sample 3 and 3CC (b), and sample 1 and 1 CC (d).

Table 3. The values of the storage modulus $G^{\prime}$ and the dynamic viscosity $\eta$ determined on the basis of non-isothermal measurements at critical temperatures.

\begin{tabular}{|c|c|c|c|c|c|c|}
\hline & \multicolumn{3}{|c|}{ Storage Modulus G' [Pa] } & \multicolumn{3}{|c|}{ Dynamic Viscosity [Pa.s] } \\
\hline & $5{ }^{\circ} \mathrm{C}$ & $20^{\circ} \mathrm{C}$ & $37^{\circ} \mathrm{C}$ & $5^{\circ} \mathrm{C}$ & $20^{\circ} \mathrm{C}$ & $37^{\circ} \mathrm{C}$ \\
\hline Sample 3 & 1.72 & 1.00 & 14.38 & 1.18 & 0.63 & 1.72 \\
\hline \multirow[t]{2}{*}{ Sample 3CC } & 3.68 & 1.53 & 8020.80 & 2.00 & 1.08 & 1604.20 \\
\hline & \multicolumn{3}{|c|}{$\begin{array}{l}\text { Experimentally Determined } \\
\text { Gelation Temperature Tgel }\left[{ }^{\circ} \mathrm{C}\right]\end{array}$} & \multicolumn{2}{|c|}{$\begin{array}{l}\text { Storage Modulus } \mathrm{G}^{\prime} \\
{[\mathrm{Pa}] \text { at Tgel }}\end{array}$} & $\begin{array}{l}\text { Dynamic Viscosity } \\
{[\mathrm{Pa} \cdot \mathrm{s}] \text { at Tgel }}\end{array}$ \\
\hline Sample 3 & \multicolumn{3}{|c|}{35.4} & \multicolumn{2}{|c|}{4.25} & 0.85 \\
\hline Sample 3CC & \multicolumn{3}{|c|}{29.6} & \multicolumn{2}{|c|}{7.00} & 1.41 \\
\hline
\end{tabular}




\subsection{Structural Properties}

\subsubsection{SEM Morphology}

SEM images of the prepared chitosan scaffolds are shown in Figure 9. It can be seen that the concentration of calcium $\beta$-glycerophosphate salt has a significant influence on the scaffold architecture. An increase in the concentration of calcium $\beta$-glycerophosphate causes higher corrugation and cornification of the structure as well as reduction of pore diameters, i.e., significant surface development. In the case of the highest concentrations of calcium $\beta$-glycerophosphate (samples 4 and 5), no additional porosities were observed in the scaffold structure. For comparison, scaffolds completely devoid of calcium $\beta$-glycerophosphate form vast, flat geometries with numerous smaller pores; shown in Figure 9a.

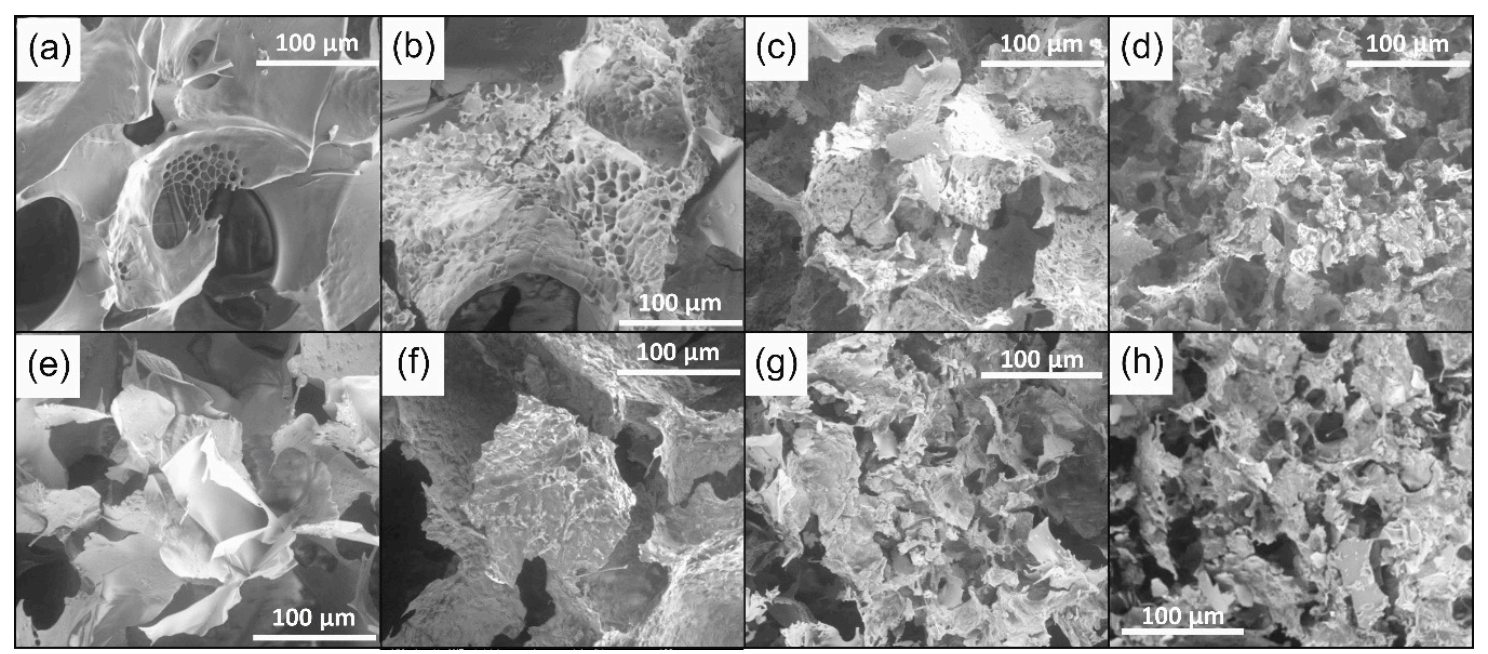

Figure 9. Microscopic images of chitosan scaffolds at 500× magnification: (a) sample 1, (b) sample 3, (c) sample 4, (d) sample 5, (e) sample 1CC, (f) sample 3CC, (g) sample 4CC, and (h) sample 5CC.

It was found that among scaffolds containing calcium $\beta$-glycerophosphate, the best and most developed structure had the scaffold prepared from a solution containing $0.1 \mathrm{~mol} / \mathrm{dm}^{3}$ of this salt, as shown in sample 3 (Figure $9 \mathrm{~b}$ ). The use of this concentration made it possible to obtain pores of two sizes: large ones of approx. $100 \mu \mathrm{m}$ and numerous smaller pores with dimensions from several to a dozen $\mu \mathrm{m}$, whose presence should positively affect the growth and proliferation of cells. An additional source of calcium has a slight effect on the obtained scaffold architecture. Regardless of the concentration of calcium glycerophosphate salt used, it was found that calcium carbonate is deposited on the surface of the resulting chitosan scaffolds in the form of flakes (Figure 9e-h), simultaneously not altering the resulting spatial structure (cf. Figure $9 a-d$ ), without the addition of calcium carbonate.

\subsubsection{EDS Analysis}

Table 4 shows the results of the analysis of elemental composition of the surface layer, determined using the EDS technique. On the basis of the obtained results, it was found that the introduction of an additional source of calcium in the form of calcium carbonate made it possible to obtain a ratio of calcium to phosphorus ions equal to (1.6-1.8):1. Such a ratio corresponds to calcium-phosphate ceramics commonly used in tissue engineering $[63,64]$. 
Table 4. Results for EDS analysis.

\begin{tabular}{cccccc}
\hline \multirow{2}{*}{$\begin{array}{c}\text { Number of } \\
\text { Sample }\end{array}$} & \multicolumn{2}{c}{ Atomic Composition \% (Standard Deviation) } & Calcium/Phosphorus \\
\cline { 2 - 4 } & Carbon & Oxygen & Phosphorus & Calcium & Ratio \\
\hline Sample no. 3CC & $47.75(2.67)$ & $42.71(1.03)$ & $2.63(0.98)$ & $4.33(1.86)$ & 1.65 \\
Sample no. 4CC & $45.59(0.72)$ & $44.55(0.24)$ & $3.54(0.19)$ & $6.32(0.40)$ & 1.79 \\
Sample no. 5CC & $36.48(1.52)$ & $48.10(0.41)$ & $5.94(0.25)$ & $9.48(1.54)$ & 1.60 \\
\hline
\end{tabular}

\subsubsection{XPS Study}

Example of the wide scan XPS spectrum, dependence of intensity against the binding energy, obtained for the scaffold enriched with calcium carbonate (sample 5CC), is shown in Figure 10. While qualitatively analyzing the results, the peaks typical for phosphates, including the hydroxyapatite, was determined [65]. The spectra reveal the formation of chitosan-calcium phosphate composites. From the quantitative analysis (Table 5), it follows that on the tested sample surface, the ratio of calcium (13.3 mass concentration \%) to phosphorus (8.26 mass concentration \%) is approx. 1.6:1-cf. Table 5 . It can therefore be assumed that, in quantitative terms, a structure similar to hydroxyapatite was obtained.

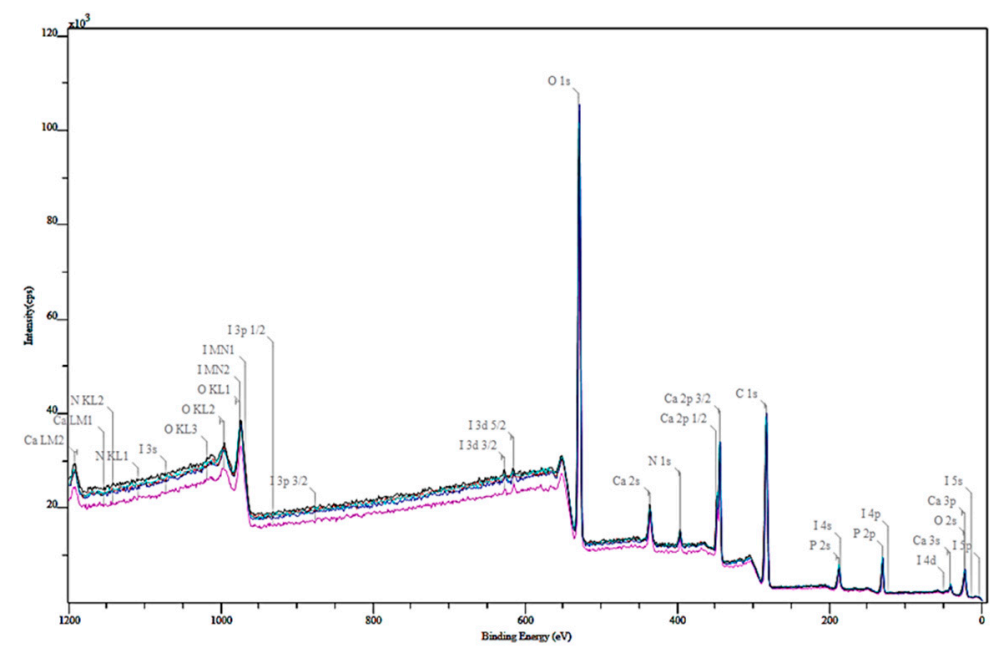

Figure 10. XPS spectrum of a sample 5CC.

Table 5. Detailed data of XPS analysis for considered peaks—sample 5CC.

\begin{tabular}{ccccccc}
\hline \multirow{2}{*}{ Peak } & \multicolumn{2}{c}{ Position BE (eV) } & \multicolumn{2}{c}{ FWHM (eV) } & \multicolumn{2}{c}{ Mass Conc \% } \\
\cline { 2 - 7 } & Value & SD * & Value & SD & Value & SD \\
\hline O 1s & 532.65 & 0.06 & 3.00 & 0.01 & 41.01 & 1.00 \\
Ca 2p & 399.28 & 0.07 & 1.44 & 0.07 & 13.30 & 0.17 \\
P 2p & 347.25 & 0.05 & 1.33 & 0.01 & 8.26 & 0.18 \\
C 1s & 286.41 & 0.07 & 1.41 & 0.05 & 35.57 & 1.17 \\
N 1s & 133.15 & 0.09 & 1.65 & 0.04 & 1.86 & 0.05 \\
\hline \multicolumn{3}{c}{ *SD_Standard Deviation. }
\end{tabular}

This value confirms the results obtained using the EDS technique-cf. Table 4 . This proves the importance of introducing calcium carbonate into chitosan solutions with $\beta$-glycerophosphate as an additional source of calcium.

\section{Conclusions}

On the basis of the conducted tests, it has been found that it is possible to prepare thermosensitive chitosan hydrogels completely devoid of disodium $\beta$-glycerophosphate salts. The use of only calcium 
$\beta$-glycerophosphate during the preparation of chitosan hydrogels followed from the fact that this compound combined the benefits of buffering properties of glycerophosphate while replacing at the same time the harmful sodium ions with calcium ions. It was also shown that the use of identical concentrations of two glycerophosphate salts with sodium and calcium atoms caused a rapid change in viscoelastic properties and different conditions of phase transition of colloidal chitosan solutions. Analysis of the results of research carried out for various concentrations of calcium $\beta$-glycerophosphate has shown that the use of four times lower concentration of calcium $\beta$-glycerophosphate, relative to the molar concentration of sodium salt commonly used in studies published in the literature [19,33], makes it possible to obtain a colloidal solution that undergoes phase transition at a temperature of about $35^{\circ} \mathrm{C}$. The dependence of the position of the gelation point on the concentration of calcium $\beta$-glycerophosphate is similar to the one presented in the literature for solutions containing disodium $\beta$-glycerophosphate $[19,33]$. However, the obtained values of phase transition temperatures are much lower, as shown in Figure $3 \mathrm{~b}$.

The introduction of an additional source of calcium in the form of calcium carbonate to the experimental medium caused a change in its rheological properties, namely a decrease of phase transition temperature, as shown in Figure 7, and an increase of mechanical resistance of the obtained scaffolds, as shown in Figure 8 and Table 3. It is worth mentioning that this change significantly depended on the used concentration of calcium glycerophosphate salt. It turned out that the 3CC sample best meets the requirements for injection scaffolds in tissue engineering applications.

The conducted studies, based on the Zeta potential curves, allowed to clearly determine that the type of glycerophosphate salt (the valency of the cation forming it) has an important role in the stability of the colloidal system. This effect is more visible in the gelation region (above $30^{\circ} \mathrm{C}$ ), where in the case of solutions containing calcium glycerophosphate, coagulation of particles occurs. This phenomenon was not observed with commonly used sodium glycerophosphate.

The conducted analyses of elemental composition of the surface layer by EDS and XPS techniques confirmed that the obtained chitosan-hydroxyapatite composite had a calcium to phosphorus ratio characteristic for this type of bioceramics which amounted to approx. 1.6:1. Analysis of the morphology of the scaffolds indicates that the scaffolds for tissue culture have a highly interconnected surface and spatial structure characterized by two classes of pore size. The use of calcium $\beta$-glycerophosphate instead of sodium $\beta$-glycerophosphate salt enables wider use of thermosensitive chitosan hydrogels in bone tissue engineering. It results from the preparation of scaffolds with much better mechanical properties, which simultaneously contain tissue-generating elements in proportions characteristic for chemical compounds which are natural building materials of bone tissue.

The conducted research provides new valuable information both in terms of application as well as for the mechanism of sol-gel phase transitions of colloidal chitosan solutions, which is still discussed in the literature.

\section{Patents}

The research presented in the manuscript has been submitted for patent protection at Patent Office of the Republic of Poland (P.423822).

Author Contributions: Conceptualization, P.O., A.R. and M.D.; Data curation, P.O. and A.R.; Formal analysis, P.O. and A.R.; Investigation, P.O., A.R. and J.S.; Methodology, P.O. and A.R.; Resources, P.O. and M.D.; Supervision, M.D.; Visualization, A.R.; Writing—original draft, P.O. and A.R.; Writing—review \& editing, P.O. and A.R.

Funding: This research received no external funding.

Acknowledgments: The authors would like to thank Jacek Balcerzak for performing XPS measurements and useful discussions.

Conflicts of Interest: The authors declare no conflict of interest. 


\section{References}

1. Hollister, S.J. Porous scaffold design for tissue engineering. Nat. Mater. 2005, 4, 518. [CrossRef] [PubMed]

2. Garg, T.; Singh, O.; Arora, S.; Murthy, R. Scaffold: A novel carrier for cell and drug delivery. Crit. Rev. Ther. Drug Carr. Syst. 2012, 29, 1-63. [CrossRef]

3. Dash, M.; Chiellini, F.; Ottenbrite, R.M.; Chiellini, E. Chitosan-A versatile semi-synthetic polymer in biomedical applications. Prog. Polym. Sci. 2011, 36, 981-1014. [CrossRef]

4. Di Martino, A.; Sittinger, M.; Risbud, M.V. Chitosan: A versatile biopolymer for orthopaedic tissue-engineering. Biomaterials 2005, 26, 5983-5990. [CrossRef]

5. Paul, W.; Sharma, C.P. Chitosan, a drug carrier for the 21st century: A review. STP Pharma Sci. 2000, 10, 5-22.

6. Sahoo, D.; Sahoo, S.; Mohanty, P.; Sasmal, S.; Nayak, P.L. Chitosan: A New Versatile Bio-polymer for Various Applications. Des. Monomers Polym. 2009, 12, 377-404. [CrossRef]

7. Chirkov, S.N. The Antiviral Activity of Chitosan (Review). Appl. Biochem. Microbiol. 2002, 38, 1-8. [CrossRef]

8. Ing, L.Y.; Zin, N.M.; Sarwar, A.; Katas, H. Antifungal Activity of Chitosan Nanoparticles and Correlation with Their Physical Properties. Available online: https://www.hindawi.com/journals/ijbm/2012/632698/ (accessed on 16 December 2017).

9. No, H.K.; Young Park, N.; Ho Lee, S.; Meyers, S.P. Antibacterial activity of chitosans and chitosan oligomers with different molecular weights. Int. J. Food Microbiol. 2002, 74, 65-72. [CrossRef]

10. Rabea, E.I.; Badawy, M.E.-T.; Stevens, C.V.; Smagghe, G.; Steurbaut, W. Chitosan as antimicrobial agent: Applications and mode of action. Biomacromolecules 2003, 4, 1457-1465. [CrossRef]

11. Cheung, R.C.F.; Ng, T.B.; Wong, J.H.; Chan, W.Y. Chitosan: An Update on Potential Biomedical and Pharmaceutical Applications. Mar. Drugs 2015, 13, 5156-5186. [CrossRef]

12. Dutta, P.K.; Dutta, J.; Tripathi, V.S. Chitin and chitosan: Chemistry, properties and applications. J. Sci. Ind. Res. 2004, 63, 20-31.

13. Friedman, A.J.; Phan, J.; Schairer, D.O.; Champer, J.; Qin, M.; Pirouz, A.; Blecher-Paz, K.; Oren, A.; Liu, P.T.; Modlin, R.L.; et al. Antimicrobial and anti-inflammatory activity of chitosan-alginate nanoparticles: A targeted therapy for cutaneous pathogens. J. Investig. Dermatol. 2013, 133, 1231-1239. [CrossRef]

14. Gibot, L.; Chabaud, S.; Bouhout, S.; Bolduc, S.; Auger, F.A.; Moulin, V.J. Anticancer properties of chitosan on human melanoma are cell line dependent. Int. J. Biol. Macromol. 2015, 72, 370-379. [CrossRef]

15. Pan, H.; Yang, Q.; Huang, G.; Ding, C.; Cao, P.; Huang, L.; Xiao, T.; Guo, J.; Su, Z. Hypolipidemic effects of chitosan and its derivatives in hyperlipidemic rats induced by a high-fat diet. Food Nutr. Res. 2016, 60. [CrossRef] [PubMed]

16. Qi, L.; Xu, Z. In vivo antitumor activity of chitosan nanoparticles. Bioorg. Med. Chem. Lett. 2006, 16, 4243-4245. [CrossRef] [PubMed]

17. Yen, M.-T.; Yang, J.-H.; Mau, J.-L. Antioxidant properties of chitosan from crab shells. Carbohydr. Polym. 2008, 74, 840-844. [CrossRef]

18. Chenite, A.; Chaput, C.; Wang, D.; Combes, C.; Buschmann, M.D.; Hoemann, C.D.; Leroux, J.C.; Atkinson, B.L.; Binette, F.; Selmani, A. Novel injectable neutral solutions of chitosan form biodegradable gels in situ. Biomaterials 2000, 21, 2155-2161. [CrossRef]

19. Cho, J.; Heuzey, M.-C.; Bégin, A.; Carreau, P.J. Physical gelation of chitosan in the presence of beta-glycerophosphate: The effect of temperature. Biomacromolecules 2005, 6, 3267-3275. [CrossRef]

20. Lavertu, M.; Filion, D.; Buschmann, M.D. Heat-induced transfer of protons from chitosan to glycerol phosphate produces chitosan precipitation and gelation. Biomacromolecules 2008, 9, 640-650. [CrossRef]

21. Qiu, X.; Yang, Y.; Wang, L.; Lu, S.; Shao, Z.; Chen, X. Synergistic interactions during thermosensitive chitosan- $\beta$-glycerophosphate hydrogel formation. RSC Adv. 2011, 1, 282-289. [CrossRef]

22. Supper, S.; Anton, N.; Seidel, N.; Riemenschnitter, M.; Schoch, C.; Vandamme, T. Rheological Study of Chitosan/Polyol-phosphate Systems: Influence of the Polyol Part on the Thermo-Induced Gelation Mechanism. Langmuir 2013, 29, 10229-10237. [CrossRef]

23. Wang, T.; Turhan, M.; Gunasekaran, S. Selected properties of $\mathrm{pH}$-sensitive, biodegradable chitosan-poly(vinyl alcohol) hydrogel. Polym. Int. 2004, 53, 911-918. [CrossRef]

24. Zhu, Y.-J.; Chen, F. pH-Responsive Drug-Delivery Systems. Chem. Asian J. 2015, 10, 284-305. [CrossRef] 
25. Kim, S.; Kang, Y.; Mercado-Pagán, Á.E.; Maloney, W.J.; Yang, Y. In vitro evaluation of photo-crosslinkable chitosan-lactide hydrogels for bone tissue engineering. J. Biomed. Mater. Res. Part B Appl. Biomater. 2014, 102, 1393-1406. [CrossRef]

26. Jeong, B.; Kim, S.W.; Bae, Y.H. Thermosensitive sol-gel reversible hydrogels. Adv. Drug Deliv. Rev. 2012, 64, 154-162. [CrossRef]

27. Liu, M.; Zeng, X.; Ma, C.; Yi, H.; Ali, Z.; Mou, X.; Li, S.; Deng, Y.; He, N. Injectable hydrogels for cartilage and bone tissue engineering. Bone Res. 2017, 5, 17014. [CrossRef]

28. Solouk, A.; Mirzadeh, H.; Amanpour, S. Injectable scaffold as minimally invasive technique for cartilage tissue engineering: In vitro and in vivo preliminary study. Prog. Biomater. 2014, 3, 143-151. [CrossRef]

29. Drury, J.L.; Mooney, D.J. Hydrogels for tissue engineering: Scaffold design variables and applications. Biomaterials 2003, 24, 4337-4351. [CrossRef]

30. Hennink, W.E.; van Nostrum, C.F. Novel crosslinking methods to design hydrogels. Adv. Drug Deliv. Rev. 2002, 54, 13-36. [CrossRef]

31. Zaccone, A.; Winter, H.H.; Siebenbürger, M.; Ballauff, M. Linking self-assembly, rheology, and gel transition in attractive colloids. J. Rheol. 2014, 58, 1219-1244. [CrossRef]

32. Owczarz, P.; Ziółkowski, P.; Modrzejewska, Z.; Kuberski, S.; Dziubiński, M. Rheo-Kinetic Study of Sol-Gel Phase Transition of Chitosan Colloidal Systems. Polymers 2018, 10, 47. [CrossRef]

33. Chenite, A.; Buschmann, M.; Wang, D.; Chaput, C.; Kandani, N. Rheological characterisation of thermogelling chitosan/glycerol-phosphate solutions. Carbohydr. Polym. 2001, 46, 39-47. [CrossRef]

34. Owczarz, P.; Ziółkowski, P.; Dziubiński, M. The Application of Small-Angle Light Scattering for Rheo-Optical Characterization of Chitosan Colloidal Solutions. Polymers 2018, 10, 431. [CrossRef]

35. Filion, D.; Lavertu, M.; Buschmann, M.D. Ionization and Solubility of Chitosan Solutions Related to Thermosensitive Chitosan/Glycerol-Phosphate Systems. Biomacromolecules 2007, 8, 3224-3234. [CrossRef]

36. Eeckman, F.; Amighi, K.; Moës, A.J. Effect of some physiological and non-physiological compounds on the phase transition temperature of thermoresponsive polymers intended for oral controlled-drug delivery. Int. J. Pharm. 2001, 222, 259-270. [CrossRef]

37. Dhara, D.; Chatterji, P.R. Phase Transition in Linear and Cross-Linked Poly(N-Isopropylacrylamide) in Water: Effect of Various Types of Additives. J. Macromol. Sci. Part C 2000, 40, 51-68. [CrossRef]

38. Kamińska, M.; Kuberski, S.; Maniukiewicz, W.; Owczarz, P.; Komorowski, P.; Modrzejewska, Z.; Walkowiak, B. Thermosensitive chitosan gels containing calcium glycerophosphate for bone cell culture. J. Bioact. Compat. Polym. 2017, 32, 209-222. [CrossRef]

39. Skwarczynska, A.L.; Kuberski, S.; Maniukiewicz, W.; Modrzejewska, Z. Thermosensitive chitosan gels containing calcium glycerophosphate. Spectrochim. Acta Part A Mol. Biomol. Spectrosc. 2018, 201, $24-33$. [CrossRef]

40. Lisková, J.; Bačaková, L.; Skwarczyńska, A.L.; Musial, O.; Bliznuk, V.; De Schamphelaere, K.; Modrzejewska, Z.; Douglas, T.E.L. Development of thermosensitive hydrogels of chitosan, sodium and magnesium glycerophosphate for bone regeneration applications. J. Funct. Biomater. 2015, 6, 192-203. [CrossRef]

41. Wang, L.; Stegemann, J.P. Thermogelling chitosan and collagen composite hydrogels initiated with $\beta$-glycerophosphate for bone tissue engineering. Biomaterials 2010, 31, 3976-3985. [CrossRef]

42. Florencio-Silva, R.; Sasso, G.R.D.S.; Sasso-Cerri, E.; Simões, M.J.; Cerri, P.S. Biology of Bone Tissue: Structure, Function, and Factors That Influence Bone Cells. Available online: https://www.hindawi.com/journals/bmri/ 2015/421746/ (accessed on 16 December 2017).

43. Liu, H.; Yazici, H.; Ergun, C.; Webster, T.J.; Bermek, H. An in vitro evaluation of the Ca/P ratio for the cytocompatibility of nano-to-micron particulate calcium phosphates for bone regeneration. Acta Biomater. 2008, 4, 1472-1479. [CrossRef]

44. Silva, T.S.N.; Primo, B.T.; Silva Júnior, A.N.; Machado, D.C.; Viezzer, C.; Santos, L.A. Use of calcium phosphate cement scaffolds for bone tissue engineering: In vitro study. Acta Cir. Bras. 2011, 26, 7-11. [CrossRef]

45. Albanna, M.Z.; Bou-Akl, T.H.; Walters, H.L.; Matthew, H.W.T. Improving the mechanical properties of chitosan-based heart valve scaffolds using chitosan fibers. J. Mech. Behav. Biomed. Mater. 2012, 5, 171-180. [CrossRef]

46. Wu, G.; Yuan, Y.; He, J.; Li, Y.; Dai, X.; Zhao, B. Stable thermosensitive in situ gel-forming systems based on the lyophilizate of chitosan $/ \alpha, \beta$-glycerophosphate salts. Int. J. Pharm. 2016, 511, 560-569. [CrossRef] 
47. Venkatesan, J.; Kim, S.-K. Chitosan composites for bone tissue engineering-an overview. Mar. Drugs 2010, 8, 2252-2266. [CrossRef]

48. Kucharska, M.; Walenko, K.; Lewandowska-Szumieł, M.; Brynk, T.; Jaroszewicz, J.; Ciach, T. Chitosan and composite microsphere-based scaffold for bone tissue engineering: Evaluation of tricalcium phosphate content influence on physical and biological properties. J. Mater. Sci. Mater. Med. 2015, 26, 143. [CrossRef]

49. Shavandi, A.; Bekhit, A.E.-D.A.; Ali, M.A.; Sun, Z.; Gould, M. Development and characterization of hydroxyapatite/ $\beta-\mathrm{TCP} /$ chitosan composites for tissue engineering applications. Mater. Sci. Eng. C Mater. Biol. Appl. 2015, 56, 481-493. [CrossRef]

50. Zhang, Y.; Zhang, M. Calcium phosphate/chitosan composite scaffolds for controlled in vitro antibiotic drug release. J. Biomed. Mater. Res. 2002, 62, 378-386. [CrossRef]

51. Escobar-Sierra, D.M.; Martins, J.; Ossa-Orozco, C.P. Chitosan/hydroxyapatite scaffolds for tissue engineering manufacturing method effect comparison. Rev. Fac. De Ing. Univ. De Antioq. 2015, 24-35. [CrossRef]

52. Kong, L.; Gao, Y.; Lu, G.; Gong, Y.; Zhao, N.; Zhang, X. A study on the bioactivity of chitosan/nanohydroxyapatite composite scaffolds for bone tissue engineering. Eur. Polym. J. 2006, 42, 3171-3179. [CrossRef]

53. Zhang, J.; Nie, J.; Zhang, Q.; Li, Y.; Wang, Z.; Hu, Q. Preparation and characterization of bionic bone structure chitosan/hydroxyapatite scaffold for bone tissue engineering. J. Biomater. Sci. Polym. Ed. 2014, 25, 61-74. [CrossRef]

54. Maleki Dizaj, S.; Barzegar-Jalali, M.; Hossein Zarrintan, M.; Adibkia, K.; Lotfipour, F. Calcium Carbonate Nanoparticles; Potential in Bone and Tooth Disorders. Pharm. Sci. 2015, 20, 175-182.

55. Patel, V.R.; Agrawal, Y.K. Nanosuspension: An approach to enhance solubility of drugs. J. Adv. Pharm. Technol. Res. 2011, 2, 81-87.

56. Aoki, T.; Muramatsu, M.; Torii, T.; Sanui, K.; Ogata, N. Thermosensitive Phase Transition of an Optically Active Polymer in Aqueous Milieu. Macromolecules 2001, 34, 3118-3119. [CrossRef]

57. Cho, J.; Heuzey, M.-C.; Bégin, A.; Carreau, P.J. Chitosan and glycerophosphate concentration dependence of solution behaviour and gel point using small amplitude oscillatory rheometry. Food Hydrocoll. 2006, 20, 936-945. [CrossRef]

58. Kasapis, S.; Mitchell, J.; Abeysekera, R.; MacNaughtan, W. Rubber-to-glass transitions in high sugar/biopolymer mixtures. Trends Food Sci. Technol. 2004, 15, 298-304. [CrossRef]

59. Ferry, J.D. Viscoelastic Properties of Polymers; John Wiley \& Sons: New York, NY, USA, 1980.

60. Owczarz, P.; Rył, A.; Modrzejewska, Z.; Dziubiński, M. The influence of the addition of collagen on the rheological properties of chitosan chloride solutions. Prog. Chem. Appl. Chitin Its Deriv. 2017, 22, 176-189. [CrossRef]

61. Fredrickson, G.H.; Larson, R.G. Viscoelasticity of homogeneous polymer melts near a critical point. J. Chem. Phys. 1987, 86, 1553-1560. [CrossRef]

62. Aliaghaie, M.; Mirzadeh, H.; Dashtimoghadam, E.; Taranejoo, S. Investigation of gelation mechanism of an injectable hydrogel based on chitosan by rheological measurements for a drug delivery application. Soft Matter 2012, 8, 7128-7137. [CrossRef]

63. Bose, S.; Tarafder, S. Calcium phosphate ceramic systems in growth factor and drug delivery for bone tissue engineering: A review. Acta Biomater. 2012, 8, 1401-1421. [CrossRef]

64. Pina, S.; Oliveira, J.M.; Reis, R.L. Natural-Based Nanocomposites for Bone Tissue Engineering and Regenerative Medicine: A Review. Adv. Mater. 2015, 27, 1143-1169. [CrossRef] [PubMed]

65. Arce, J.E.; Arce, A.E.; Aguilar, Y.; Yate, L.; Moya, S.; Rincón, C.; Gutiérrez, O. Calcium phosphate-calcium titanate composite coatings for orthopedic applications. Ceram. Int. 2016, 42, 10322-10331. [CrossRef]

(C) 2019 by the authors. Licensee MDPI, Basel, Switzerland. This article is an open access article distributed under the terms and conditions of the Creative Commons Attribution (CC BY) license (http://creativecommons.org/licenses/by/4.0/). 